\title{
An Up-Date on the Molecular Biomarkers as Potential Therapeutic Targets in Human Testicular Germ Cell Tumors
}

\author{
Paolo Chieffi ${ }^{1, *}$ and Sergio Chieffi ${ }^{2}$
}

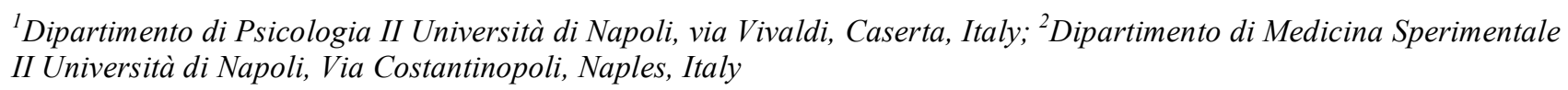

\begin{abstract}
Although testicular germ cell tumors (TGCTs) are relatively uncommon, they are particularly important as they tend to affect children and young men, representing the most common tumor in male aged from 20 to 40 years, and the incidence has increased in the last years. TGCTs comprise two major histologic groups: seminomas and non-seminomas germ cell tumors (NSGCTs). NSGCTs can be further divided into embryonal, carcinoma, teratoma, yolk sac tumor, and choriocarcinoma. Seminomas and NSGCTs present significant differences in clinical features, therapy, and prognosis, and both show characteristics of the Primordial Germ Cells (PGCs). For proper diagnosis of the different histological subgroups, immunohistochemistry is required using different molecular markers, such as HMGA1, HMGA2, Aurora B, Nek2, and others and they could represent useful novel molecular targets for antineoplastic strategies. Recent developments such as the discovery or the role of miRNAs in oncogenesis also revealed highly interesting features of TGCTs. Specific miRNAs were shown to be involved in bypassing the WT p53 pathway, which is another characteristic of TGCTs. More insight into the pathogenesis of TGCTs is likely to contribute not only to better treatment of these tumors but also to a better understanding of stem cells and oncogenesis.
\end{abstract}

Keywords: Testis, testicular cancer, gonocytes, testicular germ cells tumors, seminomas, teratoma, HMGA, Aurora B, GPR30, PATZ1.

\section{INTRODUCTION}

Testicular germ cell tumors (TGCTs) are a heterogeneous group of neoplasms seen mainly in young men. They are classified as seminomatous (SE-TGCT) and nonseminomatous (NSE-TGCT) tumors, both of which appear to arise from intratubular germ cell neoplasias (ITGCN). The former is constituted by neoplastic germ cells that retain the morphology of primordial germ cells or gonocytes, whereas NSE-TGCT displays primitive zygotic (embryonal carcinomas), embryonal-like somatically differentiated (teratomas) and extraembrionally differentiated (choriocarcinomas, yolk sac tumors) patterns [1-5]. Both these tumors derive from Intratubular Germ Cell Tumors (ITGCTs) [1-5].

Non-seminomas (NSE), including teratoma and embryonal carcinoma, contain stem cells as well as cells that have differentiated toward somatic lineages to various degrees, thus giving rise to a morphologically pleiotropic appearance [1]. In contrast, seminomas have an apparently homogenous cell composition. In addition, the cells present in seminomas are like the PGCs and/or the cells in ITGCTs. Thus, genes expressed in seminomas are interesting not only to understand their role in the oncogenesis, but also for research into PGCs [4].

The incidence of TGCT in western countries has increased in the last years [6]. In addition, differences in incidence between adjacent countries such as Finland and

\footnotetext{
*Address correspondence to this author at the Dipartimento di Psicologia, Viale Ellittico, 81100 Caserta, Italy; Tel: 39-81-566-5803; Fax: 39-81-566-7500; E-mail: Paolo.Chieffi@unina2.it
}

1876-827X/13
Sweden are still largely unexplained. Both clinical and epidemiological evidences strongly suggest that environmental and genetic factors play an important role in the genesis and development of TGCTs. It has been demonstrated that different genes have a role in the pathogenesis of TGCTs, but the involvement of other genetic factors remains unknown $[7,8]$. Genetic susceptibility and environmental factors may deregulate normal differentiation processes of PGCs. In fact, TGCTs have an invasive phenotype and are believed to be derived from a common ancestor, carcinoma in situ (CIS), where the generation and expansion of tumor cells are limited to the seminiferous tubules [9].

This mini-review will describe on the molecular alterations identified in post-pubertal TGCTs and on novel targeted antineoplastic strategies that could contribute to cure TGCTs.

\section{SERUM TUMOR MARKERS IN TGCTS}

In recent years, although the implementation to identify novel biomarkers for progression has improved our ability to counsel our patients with regard to likely outcomes and risk and relapse, large gaps remain in our ability to reliably exclude patients from unnecessary treatment or implement lifesaving therapies in those destined to fail.

Three serum tumor markers, S- alpha fetoprotein (S-AFP) concentration, S-human-chorionic gonadotropin (S-hCG), and serum lactate dehydrogenase (S-LD) catalytic concentration, are currently used as prognostic markers. [10]. In the fetus, AFP is a major serum-binding protein produced by the fetal yolk sac, liver, and gastrointestinal tract. The highest concentrations approach during the $12^{\text {th }}$ to $14^{\text {th }}$ weeks 
of gestation and decline 1 year after birth [10]. AFP is secreted by embryonal cell carcinoma and yolk sac tumor, but not by pure choriocarcinoma or pure seminoma. Falsely elevated AFP values can be seen after treatment in patients with liver disease, hereditary persistence of AFP, and several malignancies including hepatocellular carcinoma, lung, pancreatic, colon, and gastric cancers [10].

During pregnancy, hCG is produced primarily by the syncytiotrophoblastic cells of the placenta and serves to maintain the corpus luteum. Similarly, in TGCTs, syncytiotrophoblastic cells are responsible for the production of hCG. All the patients with choriocarcinoma and $40 \%$ to $60 \%$ of patients with embryonal cell carcinoma have elevated serum levels of hCG. Approximately $10 \%$ to $20 \%$ of patients with pure seminoma have elevated serum hCG.

$\mathrm{S}-\mathrm{LD}$ is a cytoplasmic enzyme found in all living cells. S-LD catalyzes the reduction of pyruvate to lactate TGCTs patients typically express high levels of S-LD isoenzyme 1 (S-LD-1). However, S-DL represents a non specific marker for the burden of disease and can be elevated in non-TGCT malignancies and conditions of chronic disease, such as liver and congestive heart failure, pancreatitis, hemolytic anemia, collagen vascular disorders [10].

\section{NEW DISCOVERED BIOMARKERS DETECTED BY IMMUNOHISTOCHEMISTRY IN TGCTS SUBTYPES}

Many novel biomarkers have been described in literature that can help to discriminate the different TGCTs and they represent new potential molecular therapeutic targets. These biomarkers helpful for immunohistochemistry analysis are summarized in (Fig. 1) in order to clearly define each TGCT histotype.

HMGA1 and HMGA2 represent a useful diagnostic markers $[11,12]$. In fact, it has been demonstrated that the two isoforms are differently expressed with respect to the state of differentiation of TGCTs [11,12]. Indeed, HMGA1 is able to bind proteins involved in transcriptional regulation such as RNF4 $[13,14]$ and PATZ1 that have been shown to be delocalized and over-expressed in human testicular seminomas [15]. More recently, we have shown that PATZ1 interacts with ER $\beta$ in normal germ cells, while down regulation of ER $\beta$ is associated with transcriptional co-regulator PATZ1 delocalization in human testicular seminomas $[16,17]$.

Another marker that could help to discriminate the different TGCTs histotypes is Aurora-B expression; it has been detected in all CIS, seminomas and embryonal carcinomas analyzed but not in teratomas and yolk sac carcinomas [1820].
NEK2 is a serine/threonine kinase that promotes centrosome splitting and ensures correct chromosome segregation during the G2/M phase of the cell cycle, through phosphorylation of specific substrates. Aberrant expression and activity of NEK2 are present in neoplastic cells of seminomas. In addition, nuclear localization and the up-regulation of Nek2 protein were also observed in the TCam- 2 seminoma cell line, and correlate with expression of the stemness markers PLZF and OCT4 [21,22]. OCT3/4 is a well-characterized marker for PGCs, and of CIS, seminoma, and embryonal carcinoma [23]. It has been demonstrated that OCT3/4 is also expressed in normal adult stem cells and non-germ cellderived cancers $[23,24]$. OCT3/4 is a transcription factor of the family of octamer-binding proteins (also known as the POU homeodomain proteins) and is regarded as one of the key regulators of pluripotency [24]. In addition to OCT3/4, several other embryonic stem-cell-specific proteins are important for maintaining the so-called "stemness" of pluripotent cells, such as NANOG and SOX2 [25-27].

NANOG protein was detected in gonocytes within the developing testis. In addition, NANOG is highly and specifically expressed in CIS, embryonal carcinoma, and seminomas, but not in teratoma, and YSTs revealing a molecular and developmental link between TGCTs and the embryonic cells from which they arise [28].

SOX2 is a member of the SOX protein family, transcription factors that regulate development from the early embryonal stage to differentiated lineages of specialized cells. SOX proteins are known to cooperate with POU proteins; in particular, it has been well demonstrated the interaction between SOX2 and OCT3/4. SOX2 is not detected in human germ cells regardless of their developmental age, in contrast to data in mouse embryos [29]. SOX2 is expressed in embryonal carcinoma, but it is not present in seminomas, YSTs, and normal spermatogenesis [29]. SOX17 maps to the chromosomal region $8 \mathrm{p} 23$, which is gained in seminoma. This indicates that SOX17 is a candidate SOX protein for cooperation with OCT3/4 in CIS and seminoma. These data also demonstrate that SOX17 is a good marker to discriminate CIS and seminoma from embryonal carcinoma. Of interest is that SOX17 distinguishes embryonic from adult hematopoietic stem cells [30]. Current research focuses on the processes that may regulate the differential expression of SOX2 versus SOX17 and on the role of these SOX proteins in the different histologies of the TGCT subtypes involved $[31,32]$.

The effects of estrogens are mainly mediated by binding to $\operatorname{ER} \alpha$ and ER $\beta$ [33-35], and transcriptional stimulation of estrogen responsive genes. Recently, several reports have

\begin{tabular}{|c|c|c|c|c|c|c|c|c|c|c|}
\hline & OCT3/4 & SOX2 & SOX17 & HMGA1 & HMGA2 & PATZ1 & GPR30 & CCDC6 & Nek2 & Aur. B \\
\hline Seminoma & + & - & + & + & - & $+(C)$ & + & - & + & + \\
\hline Embr. carc. & + & + & - & + & + & $+(C)$ & + & - & $+/-$ & + \\
\hline Teratoma & - & $+/-$ & $+/-$ & - & - & $+(C)$ & $+/-$ & - & - & - \\
\hline Yolk sac & - & - & $+/-$ & - & + & $+(C)$ & + & - & - & - \\
\hline
\end{tabular}

Notes: +, expressed; +C cytoplasmic localization; -, not expressed; +/- variable expression.

Fig. (1). Immunohistochemical markers identified in TGCT subtypes. 
described estrogen/anti-estrogen binding and activation properties of the $\mathrm{G}$ protein-coupled receptor (GPR)30 which has been proposed as a candidate for triggering a broad range of biological activities. It has been shown that GPR30 is over-expressed in seminomas and in the derived human seminoma TCam-2 cell line. The design of a specific GPR30 inhibitors could be a useful molecular target to block neoplastic germ cells with a high proliferative rate suggesting its potential therapeutic role for the treatment of TGCTs [3640].

Sariola and co-workers have shown that targeted overexpression of glial cell line-derived neurotrophic factor (GDNF) in undifferentiated spermatogonia promotes malignant testicular tumors, which express germ-cell markers. The tumors are invasive and contain aneuploid cells, but no distant metastases have been found. By several histological, molecular, and histochemical characteristics, the GDNFinduced tumors mimic classic seminomas in men, representing a useful experimental model for testicular germ-cell tumors [41]. In addition, recently, it has been shown that GDNF promotes invasive behavior, an effect dependent on pericellular protease activity, possibly through the activity of matrix metalloproteinases. GFRA1 over-expression in CIS and seminoma cells, along with the functional analyses in TCam-2 cells, suggests an involvement of the GDNF pathway in the progression of testicular germ cell cancer [42].

DNA damage response has been clearly described as an anti-cancer barrier in early human tumorigenesis. Moreover, interestingly, TGCTs have been reported to lack the DNA Damage Response (DDR) pathway activation. CCDC6 is a pro-apoptotic phosphoprotein substrate of the Ataxia Telangiectasia Mutated (ATM) able to sustain DNA damage checkpoint in response to genotoxic stress and is commonly rearranged in malignancies upon fusion with different partners. Recently, it has been shown that the loss of CCDC6 expression is the most consistent feature among the TGCTs and in the TCam-2 seminoma cell line [43].

\section{MICRO-RNAS IN TGCTS}

In recent years, the role of miRNAs in carcinogenesis of human testicular cancer and germ cell development has come on the limelight [44]. It was demonstrated that knockout mice for Dicer suffered from an early decrease in germ cell number and an impaired ability to differentiate, indicating that Dicer1 and miRNAs are important for both survival and proper differentiation of male germ cells [45]. Subsequently, it was demonstrated that miRNAs 372 and 373 can overcome cell cycle arrest mediated by p53 [44]. In contrast, in TGCT, cell lines with mutated p53 or expressing low levels of p53 were shown to be negative for these miRNAs and it can be assumed that miRNAs 372 and 373 can bypass the p53 checkpoint allowing the growth of TGCT. Another interesting link on the importance of miRNAs for germ cells and GCTs came from research on the Dead end gene (DND1). Until recently, DND1 was known to regulate germcell viability and to suppress the formation of germ cell tumors. Recently Kedde et al. [46] demonstrated that DND1 counteracts miRNA-mediated destabilization of mRNAs by binding to mRNAs and prohibiting the association of miRNAs with their target sites. This underlines the important role of miRNAs and regulation of miRNA expression in germ cell development. Linger et al. [47] focused on the role of DND1 in humans and analyzed the presence of DND1 mutations in 263 human TGCTs. Further research into the functional mechanisms of miRNAs and the role of DND1 in TGCT are likely to give more interesting clues.

\section{CONCLUSIONS}

Both environmental and genetic factors play an important role in the development of TGCTs. These factors cause the deregulation of the normal differentiation processes of PGC. For proper diagnosis of the different histological subgroups, immunohistochemistry is required using different molecular markers, as HMGA1, HMGA2, Aurora B, Nek2, and others and they could represent useful novel molecular targets for antineoplastic strategies. A unique characteristic of TGCTs is their sensitivity to treatment. Although the better responses of seminomas versus non-seminomas is well reported, as the frequent recurrence of mature teratomas in residual treatment- resistant tumors highlighting the need for more effective therapies in these resistant forms. The molecular mechanisms underlying the development of TGCTs may provide new tools to specifically target neoplastic cells and could contribute to overcome acquired and intrinsic chemotherapy resistance. More insight into the pathogenesis of TGCTs is likely to contribute not only to better treatment these tumors but also to a better understanding of stem cells and oncogenesis.

\section{CONFLICT OF INTEREST}

The author(s) confirm that this article content has no conflicts of interest.

\section{ACKNOWLEDGEMENT}

Declared none.

\section{LIST OF ABBREVIATIONS}

$\begin{array}{ll}\text { TGCTs } & \text { Testicular germ cell tumors } \\ \text { NSGCTs } & =\text { Non-seminoma germ cell tumors } \\ \text { PGCs } & =\text { Primordial Germ Cells } \\ \text { CIS } & \text { Carcinoma in situ } \\ \text { ITGCTs } & \text { Intratubular Germ Cell Tumors } \\ \text { NSE } & =\text { Non-seminomas } \\ \text { S-LD } & \text { Serum lactate dehydrogenase } \\ \text { S-AFP } & \text { S- alpha fetoprotein } \\ \text { S-hCG } & \text { S-h-chorionic gonadotropin } \\ \text { GDNF } & =\text { Glial cell line-derived neurotrophic factor }\end{array}$

\section{DISCLOSURE}

"Part of this article has been published previously in Journal of Cellular Physiology Volume 228, Issue 8, pages 1641-1646, August 2013".

\section{REFERENCES}

[1] Oosterhuis JW, Looijenga LH. Testicular germ-cell tumors in a broader perspective. Nat Rev Cancer 2005; 5: 210-22.

[2] Chieffi P, Chieffi S, Franco R, Sinisi A. Recent advances in the biology of germ cell tumors: implications for the diagnosis and treatment. J Endocrinol Invest 2012; 35: 1015-20. 
[3] Chaganti RS, Houldsworth J. Genetics and biology of adult human male germ cell tumors. Cancer Res 2000; 60: 1474-82.

[4] Ulbright TM. Germ cell tumors of the gonads: a selective review emphasizing problems in differential diagnosis, newly appreciated, and controversial issues. Modern Pathol 2005; 18: S61-S79.

[5] Chieffi P, Franco R, Portella G. Molecular and cell biology of testicular germ cell tumors. Int Rev Cell Mol Biol 2009; 278: 277308.

[6] Jones RH, Vasey PA. Part II: testicular cancer-management of advanced disease. Lancet Oncol 2003; 4:738-47.

[7] Skakkebaek NE. Possible carcinoma-in-situ of the testis. Lancet 1972; $2: 516-7$

[8] Rajpert-De Meyts E, Skakkebaek NE. Pathogenesis of testicular carcinoma in situ and germ cell cancer: still more questions than answers. Int J Androl 2011; 34: e2-6.

[9] Skakkebaek NE, Berthelsen JG, Giwercman A, Muller J. Carcinoma-in-situ of the testis: possible origin from gonocytes and precursor of all types of germ cell tumours except spermatocytoma. Int J Androl 1987; 10:19-28.

[10] von Eyben FE. Laboratory markers and germ cell tumors. Crit Rev Clin Lab Sci 2003; 40: 377-427.

[11] Chieffi P, Battista S, Barchi M et al. HMGA1 and HMGA2 protein expression in mouse spermatogenesis. Oncogene 2002; 21: 364450.

[12] Franco R, Esposito F, Fedele M, et al. Detection of high mobility group proteins $\mathrm{A} 1$ and $\mathrm{A} 2$ represents a valid diagnostic marker in post-puberal testicular germ cell tumours. J Pathol 2008; 214: 5864.

[13] Pero R, Lembo F, Di Vizio D, et al. RNF4 is a growth inhibitor expressed in germ cells and lost in human testicular tumours. Am J Pathol 2001; 159: 1225-30.

[14] Pero R, Lembo F, Chieffi $P$, et al. Translational regulation of a novel testis-specific RNF4 transcript. Mol Reprod Dev 2003; 66: 1-7.

[15] Fedele M, Franco R, Salvatore G, et al. PATZ1 gene has a critical role in the spermatogenesis and testicular tumours. J Pathol 2008; 215: 39-47.

[16] Esposito F, Boscia F, Franco R, et al. Down-regulation of estrogen receptor- $\beta$ associates with transcriptional coregulator PATZ1 delocalization in human testicular seminomas. J Pathol 2011; 224: 11020 .

[17] Esposito F, Boscia F, Gigantino V, et al. The high mobility group A1-oestrogen receptor $\beta$ nuclear interaction is impaired in human testicular seminomas J Cell Physiol 2012; 227: 3749-55.

[18] Chieffi P, Troncone G, Caleo A, et al. Aurora B expression in normal testis and seminomas. J Endocrinol 2004; 181: 263-70.

[19] Esposito F, Libertini S, Franco R, et al. Aurora B expression in post-puberal testicular germ cell tumours. J Cell Physiol 2009; 221: 435-9.

[20] Portella G, Passaro C, Chieffi P. Aurora B: a new prognostic marker and therapeutic target in cancer. Curr Med Chem 2011; 18: 482-96.

[21] Barbagallo F, Paronetto MP, Franco R, et al. Increased expression and nuclear localization of the centrosomal kinase Nek2 in human testicular seminomas. J Pathol 2009; 217: 431-41

[22] Di Agostino S, Fedele M, Chieffi P, et al. Phosphorylation of high mobility group protein $\mathrm{A} 2$ by Nek kinase during the first meiotic division in mouse spermatocytes. Mol Biol Cell 2004; 15:1224-32.

[23] Ledford H. Doubts raised over stem-cell marker. Nature (London) 2007; 449: 647.

[24] Atlasi Y, Mowla SJ, Ziaee SA, Gokhale PJ, Andrews PW. OCT4 spliced variants are differentially expressed in human pluripotent and non-pluripotent cells. Stem Cells 2008; 26: 3068-74.

[25] Avilion AA, Nicolis SK, Pevny LH, Perez L, Vivian N, Lovell Badge R. Multipotent cell lineages in early mouse development depend on SOX2 function. Genes Dev 2003; 17: 126-40.

[26] Yamaguchi S, Kimura H, Tada M, Nakatsuji N, Tada T. Nanog expression in mouse germ cell development. Gene Exp Patterns 2005; 5: 639-46.
[27] de Jong J, Looijenga LH. Stem cell marker OCT3/4 in tumor biology and germ cell tumor diagnostics: history and future. Crit Rev Oncog 2006; 12: 171-203.

[28] Hart AH, Hartley L, Parker K, et al. The pluripotency homeobox gene NANOG is expressed in human germ cell tumors. Cancer 2005; 104: 2092-8.

[29] de Jong J, Stoop H, Gillis AJ, et al. Differential expression of SOX17 and SOX2 in germ cells and stem cells has biological and clinical implications. J Pathol 2008; 215: 21-30.

[30] Kim I, Saunders TL, Morrison SJ. Sox 17 dependence distinguishes the transcriptional regulation of fetal from adult hematopoietic stem cells. Cell 2007; 130: 470-83.

[31] Gashaw I, Grummer R, Klein-Hitpass L, et al. Gene signatures of testicular seminoma with emphasis on expression of ets variant gene 4. Cell Mol Life Sci 2005; 62: 2359-68.

[32] Gashaw I, Dushaj O, Behr R, et al. Novel germ cell markers characterize testicular seminoma and fetal testis. Mol Hum Reprod 2007; 13: 721-7.

[33] Chieffi P, Franco R, Fulgione D, Staibano S. PCNA in the testis of the frog, Rana esculenta: a molecular marker of the mitotic testicular epithelium proliferation. Gen Comp Endocrinol 2000; 119: 116.

[34] Chieffi P, Colucci D'Amato L, Staibano S, Franco R, Tramontano D. Estradiol-induced mitogen-activated protein kinase (extracellular signal-regulated kinase 1 and 2) activity in the frog (Rana esculenta) testis. J Endocrinol 2000; 167: 77-84.

[35] Chieffi P, Colucci-D'Amato GL, Guarino F, Salvatore G, Angelini F. 17ß- estradiol induces spermatogonial proliferation through mitogen-activated protein kinase (extracellular signal-regulated kinase 1) activity In the lizard (Podarcis s. sicula). Mol Reprod Dev 2002; 61:218-25.

[36] Franco R, Boscia F, Gigantino V, et al. GPR30 is over-expressed in post puberal testicular germ cell tumors. Cancer Biol Ther 2011; 11: 609-13

[37] Chieffi P, Chieffi S. Molecular biomarkers as potential targets for therapeutic strategies in human testicular germ cell tumours: an overview. J Cell Physiol 2013; 228, 1641-6.

[38] Vicini E, Loiarro M, Di Agostino S, et al. 2006 17- $\beta$-estradiol elicits genomic and non-genomic responses in mouse male germ cells. J Cell Physiol 2006: 238-245

[39] Chieffi P. Molecular targets for the treatment of testicular germ cell tumors. Mini Rev Med Chem 2007; 7: 755-9.

[40] Revankar CM, Cimino DF, Sklar LA, Arterburn JB, Prossnitz ER. A transmembrane intracellular estrogen receptor mediates rapid cell signaling. Science 2005; 307: 1625-30.

[41] Meng X, de Rooij DG, Westerdahl K, Saarma M, Sariola H Promotion of seminomatous tumors by targeted overexpression of glial cell line-derived neurotrophic factor in mouse testis. Cancer Res 2001; 61: 3267-71.

[42] Ferranti F, Muciaccia B, Ricci G, et al. Glial cell line-derived neurotrophic factor promotes invasive behaviour in testicular seminoma cells. Int J Androl 2012; 35: 758-68.

[43] Staibano S, Ilardi G, Leone V, et al. Critical role of CCDC6 in the neoplastic growth of testicular germ cell tumors. BMC Cancer 2013: 13: 433 .

[44] Voorhoeve PM, le Sage C, Schrier M, et al. A genetic screen implicates miRNA-372 and miRNA-373 as oncogenes in testicular germ cell tumors. Cell 2006; 124:1169-81.

[45] Maatouk DM, Loveland KL, McManus MT, Moore K, Harfe BD. Dicer1 is required for differentiation of the mouse male germline. Biol Reprod 2008; 79: 696-703.

[46] Kedde M, Strasser MJ, Boldajipour B, et al. RNA-binding protein Dnd1 inhibits microRNA access to target mRNA. Cell 2007; 131: 1273-86.

[47] Linger R, Dudakia D, Huddart R, et al. Analysis of the DND1 gene in men with sporadic and familial testicular germ cell tumors. Genes Chromosomes Cancer 2008; 47: 247-52.

This is an open access article licensed under the terms of the Creative Commons Attribution Non-Commercial License (http://creativecommons.org/licenses/by-nc/3.0/) which permits unrestricted, non-commercial use, distribution and reproduction in any medium, provided the work is properly cited. 